\title{
$\begin{array}{ll}\text { Research Square } & \text { Preprints are preliminary reports that have not undergone peer review. } \\ \text { They should not be considered conclusive, used to inform clinical practice, } & \text { or referenced by the media as validated information. }\end{array}$
}

\section{Revisiting the continuum of resistance theory in the digital age: A comparison of early and delayed respondents to the Norwegian Counties Public Health Survey}

Benjamin Clarsen ( $\square$ benjamin.clarsen@fhi.no)

Norwegian Institute of Public Health https://orcid.org/0000-0003-3713-8938

Jens Christoffer Skogen

Norwegian Institiute of Public Health

Thomas Severinus Nilsen

Norwegian Institute of Public Health

Leif Edvard Aarø

Norwegian Institute of Public Health

Research article

Keywords: Epidemiologic methods, Selection bias, Surveys and questionnaires

Posted Date: July 14th, 2020

DOI: https://doi.org/10.21203/rs.3.rs-39479/v1

License: (c) (1) This work is licensed under a Creative Commons Attribution 4.0 International License.

Read Full License

Version of Record: A version of this preprint was published at BMC Public Health on April 15th, 2021. See the published version at https://doi.org/10.1186/s12889-021-10764-2. 


\section{Abstract}

\section{Background}

The continuum of resistance model's premise is that delayed respondents to a survey are more similar to non-respondents than early respondents are. For decades, survey researchers have applied this model in attempts to evaluate and adjust for non-response bias. Despite a recent resurgence in the model's popularity, its value has not been assessed in a large online population health survey.

\section{Methods}

Respondents to the Norwegian Counties Public Health Survey in Hordaland, Norway, were divided into three groups: those who responded within 7 days of the initial email/SMS invitation (wave 1, $n=6950$ ); those who responded after 8 to 14 days and 1 reminder (wave 2, n =4950); and those who responded after 15 or more days and 2 reminders (wave $3, n=4045$ ). Logistic regression analyses were used to compare respondents' age, sex and educational level between waves, as well as the prevalence of poor general health, life dissatisfaction, mental distress, chronic health problems, weekly alcohol consumption, monthly binge drinking, daily smoking, physical activity, low social support and receipt of a disability pension.

Results

The overall response to the survey was $41.5 \%$. Respondents in wave 1 were more likely to be older, female and more highly educated than those in waves 2 and 3 . However, there were no substantial differences between waves for any health outcomes, with a maximal prevalence difference of $2.6 \%$ for weekly alcohol consumption (wave 1: $21.3 \%$, wave $3: 18.7 \%$ ).

\section{Conclusions}

There appeared to be a mild continuum of resistance for demographic variables. However, this was not reflected in health and related outcomes, which were uniformly similar across waves. The continuum of resistance model is unlikely to be useful to adjust for nonresponse bias in large online surveys of population health.

\section{Background}

Differences are likely between people that respond to public health surveys and those that do not. Among non-respondents, there is commonly a disproportionate number of young,(1-8) male,(2-10) and unmarried people, $(1,2,5,8,11-14)$ as well as those with lower education, $(1,2,5-8,10,12-15)$ and lower socioeconomic status. $(5,6,8,11,13,16)$ Non-respondents are also more likely to be smokers, $(1,4,10$, $14,17-19)$ and to have different patterns of alcohol consumption,(10,16, 20-22) poorer physical and/or mental health, $(5,7,9,10,23)$ and higher rates of mortality and morbidity. $(20,24-29)$ If researchers fail to 
account for nonresponse bias, prevalence estimates (in particular)(9) and analyses of associations between variables will likely be incorrect.

As nonresponse bias is less of a problem as survey response rates approach $100 \%$, researchers often use a variety of strategies to encourage participation, such as sending multiple reminders to non-respondents, encouraging them to complete the survey. Nevertheless, few large-scale public health surveys achieve a response rate adequate to avoid substantial nonresponse bias, which - depending on how much respondents and non-respondents differ in the outcomes of interest - is estimated to be between $70 \%$ and $90 \%$.(30) As participation rates in epidemiologic studies have been declining over time, $(2,31)$ it is increasingly important for researchers to identify and account for nonresponse bias when summarising and analysing data. Obviously, this is a major challenge because information on non-respondents is often unavailable, particularly for the outcomes of interest.

Researchers have sought methods to account for nonresponse bias for decades. In 1939, Pace proposed that the existence and direction of nonresponse bias in a given survey could be detected by comparing the responses of people who respond quickly to those who only respond after repeated contact attempts (delayed respondents).(32) This approach, often referred to as the "continuum of resistance" model,(33) is based on the presumption that people who are slow or reluctant (i.e. resistant) to complete a questionnaire are more similar to non-respondents than early respondents are.

The continuum of resistance model has resurfaced periodically in the literature since its proposal, despite having performed inconsistently under empirical testing. Some early studies supported the existence of a continuum of resistance for outcomes of interest; $(34,35)$ however, others have found that early and delayed responders do not differ at all, $(36,37)$ that associations between delayed responders and nonresponders are weak,(33) or that a continuum of resistance exists for demographic variables but not outcomes of interest.(38) Recently, the model has been applied in a number of surveys of alcohol consumption and other health behaviours, $(3,13,39-42)$ which have demonstrated significant and consistent differences between early and late respondents, for both demographic variables and outcomes of interest. In several of these surveys, investigators subsequently used weightings based on delayed respondents' data to adjust their prevalence estimates, in an effort to account for nonresponse bias.(3, $13,39,41,42)$

Given the apparent value of the continuum of resistance model in these recent studies, and because we are unaware of any investigations of the utility of the model in large public health surveys involving digital data collection, we compared early and delayed respondents of the internet-based Norwegian Counties Public Health Survey. We hypothesized that there would be a relatively higher proportion of male, young and less-educated people among late responders, and that a continuum of resistance would exist for health outcomes and behaviours related to these demographic differences.

\section{Methods}




\section{Study design and setting}

The Norwegian Counties Public Health Survey is a cross-sectional study of self-reported health, healthrelated behaviours, quality of life, and local health-related factors in the Norwegian general population. The survey was launched by the Norwegian Institute of Public Health in 2015 and is currently ongoing, covering each of Norway's 11 counties every 4 years. We performed this investigation using data collected in the county of Hordaland between the $10^{\text {th }}$ of April and the $13^{\text {th }}$ of June 2018 . The survey was approved by the Norwegian Data Protection Authority. This study is a secondary analysis of previously collected data, and according to the Health Research Act, additional ethical approval was not required.

\section{Participants}

A random sample of 38458 Hordaland County residents was selected from the National Population Register and invited to participate in this survey. To be eligible for selection, residents needed to be over 18 years of age and have their mobile telephone number and email address registered in the Norwegian Agency for Public Management and eGovernment. The sample size was determined to allow for adequate subgroup analysis on a municipal level (minimum of 400 participants per subgroup), with an expected response of $30 \%$ to $40 \%$.

The questionnaire was distributed to the sample by email and short message service (SMS) using a secure platform.(43) Non-respondents received reminders with a link to the questionnaire on the $7^{\text {th }}$ and $15^{\text {th }}$ day after the initial distribution, and the survey remained open for 5 weeks and 3 days.

\section{Variables}

- Response to questionnaire invitation: All members of the invited sample were categorised as survey respondents or non-respondents. Respondents were further categorised into one of three groups based on when they completed the questionnaire: (1) Wave 1 - completed the questionnaire prior to the first reminder; (2) Wave 2 - completed the questionnaire between the first and second reminders; (3) Wave 3 - completed the questionnaire after the second reminder.

- Gender: Male or female, as recorded in the national population register.

- Age: Categorised as 18-29, 30-39, 40-49, 50-59, 60-69 and 70 or older

- Education: Respondents were categorised according to their on highest-attained level of education: junior high school (up to and including $10^{\text {th }}$ grade), senior high school (up to and including 13th grade), university or university college (less than 4 years), and university or university college (4 or more years)

- Poor general health: Respondents were categorised as having poor general health if they reported having bad or very bad general health on a 5-point scale including very good, good, neither good nor bad, bad and very bad. 
- Dissatisfied with life: Respondents were categorised as being dissatisfied with life if they reported being quite dissatisfied or very dissatisfied on a 5-point scale with the alternatives very satisfied, quite satisfied, neither satisfied nor dissatisfied, quite dissatisfied, and very dissatisfied.

- Mental distress: Based on the five items' version of the Hopkins Symptom Checklist (HSCL-5), with four response options ranging from not at all (1 point) to extremely (4 points). We classified respondents with a mean item score greater than 2 as having high levels of mental distress.(44)

- Chronic health problems: Respondents who reported having a chronic health problem or disability that has lasted at least 6 months (including seasonal and intermittent problems).

- Daily smoking: Respondents who reported that they smoked tobacco on a daily basis

- Alcohol consumption: Based on the consumption questions of the Alcohol Use Disorders Identification Test (AUDIT).(45) Respondents were categorised into those who did and did not drink alcohol more than once a week, and those who did and did not consume six or more standard drinks ( $10 \mathrm{~g}$ ethanol) in a single session more than once a month (monthly binge drinkers).

- Receiving disability pension: Respondents who reported that they currently receive a disability pension

- Low social support: Respondents who reported that they experienced low social support using a previously described categorisation of the Oslo-3 Social Support Scale (OSS-3).(46)

- Physical activity: Based on the International Physical Activity Questionnaire (IPAQ). Respondents were classified as being physically active if they performed moderate or vigorous physical activity daily, or walked for at least 30 minutes every day.

\section{Statistical analyses}

We calculated response rates by age group and gender for each response wave. The proportion of responses returned in waves 1, 2 and 3 was calculated for age, gender and education. We performed logistical regression analyses to assess associations between respondents' wave (independent variable) and general health, life satisfaction, mental distress, social support, smoking, alcohol consumption, chronic health problems, receiving a disability pension (dependent variables).

All analyses were conducted in R (47). We used the packages nnet(48) to fit multinomial log-linear models, margins $(49)$ and effects $(50,51)$ to generate marginal effects, and ggplot2(52) to produce figures. A 95\% confidence interval $(\mathrm{Cl})$ was calculated for all estimates, and we used a significance threshold of .05 .

\section{Results}

The overall response rate to the questionnaire was $41.5 \%$, with $44 \%$ of responses received in wave $1,31 \%$ in wave 2 , and $25 \%$ in wave 3 . The response rate was substantially higher among females ( $46 \%$ ) than among males (37\%), and it was higher in older age groups (Fig. 1). 
[Figure 1 near here]

The age distribution of the invited sample, each response wave and non-responders is shown in Fig. 2. Younger people were under-represented and older people were over-represented among respondents, particularly in waves 1 and 2. Similarly, males were under-represented among respondents, particularly in waves 1 and 2 (Fig. 3).

[Figure 2 near here]

[Figure 3 near here]

There were small differences in the distribution of respondents' educational level between each wave, with wave 1 respondents having a relatively higher level than wave 2 and 3 respondents (Fig. 4).

[Figure 4 near here]

Health outcomes

Table 1 and Fig. 5 show the proportion of respondents in each wave that reported poor general health, life dissatisfaction, mental distress, chronic health problems, drinking alcohol more than once per week, monthly binge drinking, daily smoking, physical activity, low social support, and receiving a disability pension. Table 2 shows the results of pairwise comparisons of each wave using logistic regression analyses.

[Figure 5 near here] 
Table 1

Prevalence (\%, $[95 \% \mathrm{Cl}])$ of health and health-related outcomes among respondents in waves 1,2 and 3

\begin{tabular}{|llll|}
\hline & Wave 1 & Wave 2 & Wave 3 \\
\hline Poor general health & $7.8[7.1,8.5]$ & $6.5[5.7,7.3]^{\star}$ & $7.5[6.6,8.5]$ \\
\hline Dissatisfied with life & $4.2[3.7,4.7]$ & $3.0[2.5,3.6]^{\star}$ & $3.9[3.3,4.6]$ \\
\hline Mental distress & $11.5[10.7,12.4]$ & $9.9[9.0,10.9]^{\star}$ & $12.3[11.2,13.5]^{\#}$ \\
\hline Chronic health problems & $10.1[9.3,10.9]$ & $9.0[8.1,9.9]$ & $8.8[7.8,9.8]^{\star}$ \\
\hline Alcohol > 1x week & $21.3[20.2,22.4]$ & $19.5[18.3,20.8]^{\star}$ & $18.7[17.3,20.0]^{\star}$ \\
\hline Monthly binge drinking & $17.8[16.7,18.8]$ & $16.5[15.3,17.7]$ & $18.4[17.0,19.8]$ \\
\hline Daily smoking & $8.2[7.4,8.9]$ & $9.2[8.3,10.1]$ & $9.6[8.6,10.6]^{\star}$ \\
\hline Physically active & $35.6[34.3,37.0]$ & $36.8[35.1,38.4]$ & $35.0[33.2,36.8]$ \\
\hline Low social support & $11.6[10.7,12.4]$ & $10.5[9.6,11.5]$ & $12.1[11.0,13.2]$ \\
\hline Disability pension & $8.2[7.5,9.0]$ & $7.7[6.9,8.5]$ & $7.9[7.0,8.9]$ \\
\hline * Sig. different to wave $1(p<0.05)$ & & \\
\hline \# Sig. difference between wave 2 and wave $3(p<0.05)$ & \\
\hline
\end{tabular}

Table 2

Results of logistic regression models (odds ratios [95\% confidence interval])

\begin{tabular}{|llll|}
\hline & Wave 1 (ref.) & Wave 2 & Wave 3 \\
\hline Poor general health & 1.00 & $0.82[0.70,0.96]^{\star}$ & $0.96[0.82,1.13]$ \\
\hline Dissatisfied with life & 1.00 & $0.72[0.57,0.90]^{\star}$ & $0.94[0.75,1.17]$ \\
\hline Mental distress & 1.00 & $0.84[0.74,0.97]^{\star}$ & $1.08[0.94,1.24]$ \\
\hline Chronic health problems & 1.00 & $0.88[0.77,1.01]$ & $0.86[0.74,1.00]^{\star}$ \\
\hline Daily smoking & 1.00 & $1.14[0.99,1.32]$ & $1.19[1.02,1.39]^{\star}$ \\
\hline Alcohol >1x week & 1.00 & $0.90[0.81,0.99]^{\star}$ & $0.85[0.76,0.95]^{\star}$ \\
\hline Monthly binge drinking & 1.00 & $0.91[0.82,1.02]$ & $1.05[0.93,1.17]$ \\
\hline Physically active & 1.00 & $1.05[0.96,1.15]$ & $0.97[0.88,1.07]$ \\
\hline Low social support & 1.00 & $0.90[0.79,1.03]$ & $1.05[0.92,1.20]$ \\
\hline Disability pension & 1.00 & $0.93[0.80,1.08]$ & $0.96[0.82,1.13]$ \\
\hline *p<0.05 & & & \\
\hline
\end{tabular}




\section{Discussion}

To our knowledge, this is the first application of the continuum of resistance model to a large online public health survey. We investigated differences between respondents who completed the questionnaire within the first 7 days (wave 1), those who completed it after 8 to 15 days and one reminder (wave 2) and those who completed it after 16 or more days and two reminders (wave 3 ). For demographic variables, we identified differences between waves that were consistent with previous literature. $(1-10,12-15)$ However, differences in health outcomes and behaviours were small between waves and unlikely to be useful in correcting for nonresponse bias.

Overall, females and older people were more likely to respond to the questionnaire than males and younger people were. This was most pronounced among wave 1 and 2 respondents, whereas wave 3 more closely resembled the invited sample, containing a higher proportion of males and younger people. However, it is important to note that for sex and age, the composition of wave 3 more closely resembled waves 1 and 2 than it did the non-responders.

For education, our findings were similar. There was a slight trend towards wave 1 respondents being more highly educated than those in wave 2 and 3 . However, the difference between respondents and nonrespondents is likely to be far more substantial than the small differences between response waves. Although we lacked direct information on the education level of non-respondents, data from Statistics Norway show that $35 \%$ of Hordaland county residents have tertiary education, and that $24 \%$ have only completed junior high school.(53) These proportions differ markedly from our results (52\% and $13 \%$, respectively), suggesting that non-respondents had far lower levels of education than respondents did.

Based on the continuum of resistance model, we expected that late responders would display an overall pattern of poorer health across health outcomes. This has been found in a number of recent studies. For example, compared to early responders, late responders have been found to have a $21-68 \%$ higher prevalence of monthly binge drinking, $(3,39,41,42)$ a $30 \%$ higher prevalence of current smokers, $(54)$ and a $50 \%$ higher prevalence of people who complete less than 30 min per day of physical activity.(39) We aligned our outcome definitions to facilitate comparisons with these studies, but did not find the same results. There was no difference between waves in the prevalence of monthly binge drinking or physical inactivity, and for current smoking, the difference in prevalence between waves 1 and 3 was only 1.4 percentage points. Our findings were similar for other health outcomes; in some cases, there were statistically significant but very small prevalence differences between waves, and in others there were none at all.

There are several potential explanations for why we did not find evidence to support a continuum of resistance in our data. Indeed, it is possible that the health status of responders and non-responders is very similar in our population. We believe this is unlikely, particularly considering the findings of Knudsen et al., who, in 2008, reported a substantially higher prevalence of mental and somatic health disorders among non-responders to a health survey conducted in Hordaland county.(9) Our definition of late responders differs from recent studies demonstrating a continuum-of-resistance, which have used more 
reminders,(42) longer follow-up periods,(3, 12,39-41) and/or alternative methods such as telephone calls to contact slow responders. $(3,40,41)$ To our knowledge, this is the only continuum-of-resistance study besides those of Kypri et al. $(39,40)$ to collect data using purely digital means, and it is the first general population survey to do so. It is possible that the barriers to questionnaire completion differ between postal, telephone and internet/smartphone surveys, and that the data collection method has consequences on any eventual continuum of resistance.

This study has limitations that may have affected our findings. First, we had no information about the health status of non-responders, but rather we assumed that there were differences based on previous research. Future studies linking survey data with other sources, such as national registers, are necessary to gain more information on the health status of non-responders. Additionally, to be eligible for inclusion in the survey, people had to have their digital contact information registered with the Norwegian authorities. This introduces a selection bias that is particularly pronounced among older people, as less than $50 \%$ of Norwegian residents aged over 75 years are registered, compared to approximately $80 \%$ of those aged between 18 and 65 years.(55) It is therefore likely that the health status of the survey sample is more homogeneous than it is in the general population.

\section{Conclusion}

In this study, we were unable to identify meaningful differences in reported health and health determinants between early and late survey respondents. Assuming there are true differences in the health status of responders and non-responders, the results of delayed responders provided little help in estimating the direction or magnitude of non-response bias. Keeping the survey open for an extended period and using multiple reminders increased the overall proportion of male, younger and less-educated respondents. However, this did not appear to make the data much more representative.

\section{Declarations}

\section{Ethics approval and consent to participate}

The survey was approved by the Norwegian Data Protection Authority. This study is a secondary analysis of previously collected data, and according to the Norwegian Health Research Act, additional ethical approval was not required.

\section{Consent for publication}

Not Applicable

\section{Availability of data and materials}


Data are available from the authors based on application in accordance with Norwegian laws and regulations pertaining to health research and GDPR, and with permission of the Norwegian Institute of Public Health.

\section{Competing interests}

The authors declare that they have no competing interests

\section{Funding}

All authors completed this work within their normal employment at the Norwegian Institute of Public Health. No additional sources of funding were received.

\section{Authors' contributions}

All authors were involved in planning the study. Data were collected by TSN, LEÅ and JCS. BC analysed the data and wrote the draft manuscript. All authors contributed to and approved the final manuscript.

\section{Acknowledgements}

The authors wish to thank the Hordaland County Council, who were instrumental in funding, planning and implementing the 2018 Norwegian Counties Public Health Survey in Hordaland.

\section{References}

1. Tolonen H, Dobson A, Kulathinal S. Effect on Trend Estimates of the Difference between Survey Respondents and Non-respondents: Results from 27 Populations in the WHO MONICA Project. Eur J Epidemiol. 2005;20(11):887-98.

2. Tolonen H, Helakorpi S, Talala K, Helasoja V, Martelin T, Prättälä R. 25-year Trends and Sociodemographic Differences in Response Rates: Finnish Adult Health Behaviour Survey. Eur J Epidemiol. 2006;21(6):409-15.

3. Maclennan B, Kypri K, Langley J, Room R. Non-response bias in a community survey of drinking, alcohol-related experiences and public opinion on alcohol policy. Drug Alcohol Depend. 2012;126(12):189-94.

4. Abrahamsen R, Svendsen MV, Henneberger PK, Gundersen GF, Torén K, Kongerud J, et al. Nonresponse in a cross-sectional study of respiratory health in Norway. BMJ Open. 2016;6(1):e009912.

5. Lundberg I, Damström Thakker K, Hällström T, Forsell Y. Determinants of non-participation, and the effects of non-participation on potential cause-effect relationships, in the PART study on mental 
disorders. Soc Psychiatry Psychiatr Epidemiol. 2005;40(6):475-83.

6. Søgaard AJ, Selmer R, Bjertness E, Thelle D. The Oslo Health Study: The impact of self-selection in a large, population-based survey. International Journal for Equity in Health. 2004;3(1).

7. Van Den Akker M. Morbidity in responders and non-responders in a register-based population survey. Fam Pract. 1998;15(3):261-3.

8. Nummela O, Sulander T, Helakorpi S, Haapola I, Uutela A, Heinonen H, et al. Register-based data indicated nonparticipation bias in a health study among aging people. J Clin Epidemiol. 2011;64(12):1418-25.

9. Knudsen AK, Hotopf M, Skogen JC, Overland S, Mykletun A. The Health Status of Nonparticipants in a Population-based Health Study: The Hordaland Health Study. Am J Epidemiol. 2010;172(11):1306-14.

10. Cheung KL, Ten Klooster PM, Smit C, De Vries H, Pieterse ME. The impact of non-response bias due to sampling in public health studies: A comparison of voluntary versus mandatory recruitment in a Dutch national survey on adolescent health. BMC Public Health. 2017;17(1).

11. Bergstrand R, Vedin A, Wilhelmsson C, Wilhelmsen L. Bias due to non-participation and heterogenous sub-groups in population surveys. J Chronic Dis. 1983;36(10):725-8.

12. Korkeila K, Suominen S, Ahvenainen J, Ojanlatva A, Rautava P, Helenius H, et al. Non-response and related factors in a nation-wide health survey. Eur J Epidemiol. 2001;17(11):991-9.

13. Zhao J, Stockwell T, Macdonald S. Non-response bias in alcohol and drug population surveys. Drug Alcohol Rev. 2009;28(6):648-57.

14. Enzenbach C, Wicklein B, Wirkner K, Loeffler M. Evaluating selection bias in a population-based cohort study with low baseline participation: the LIFE-Adult-Study. BMC Med Res Methodol. 2019;19(1):135.

15. Rodes A, Sans S, Balaña LL, Paluzie G, Aguilera R, Balaguer-Vintro I. Recruitment methods and differences in early, late and non-respondents in the first MONICA-Catalonia population survey. Rev Epidemiol Sante Publique. 1990;38(5-6):447-53.

16. Ohlson CG, Ydreborg B. Participants and non-participants of different categories in a health survey. A cross-sectional register study. Scand J Soc Med. 1985;13(2):67-74.

17. Criqui $\mathrm{MH}$, Barrett-Connor $\mathrm{E}$, Austin M. Differences between respondents and non-respondents in a population-based cardiovascular disease study. Am J Epidemiol. 1978;108(5):367-72.

18. Helakorpi S, Makela P, Holstila A, Uutela A, Vartiainen E. Can the accuracy of health behaviour surveys be improved by non-response follow-ups? The European Journal of Public Health. 2015;25(3):487-90.

19. Rönmark E, Lundqvist A, Lundbäck B, Nyström L. Non-responders to a postal questionnaire on respiratory symptoms and diseases. Eur J Epidemiol. 1999;15(3):293-9.

20. Tolonen H, Laatikainen T, Helakorpi S, Talala K, Martelin T, Prättälä R. Marital status, educational level and household income explain part of the excess mortality of survey non-respondents. Eur $\mathrm{J}$ 
Epidemiol. 2010;25(2):69-76.

21. Wild TC, Cunningham J, Adlaf E. Nonresponse in a follow-up to a representative telephone survey of adult drinkers. J Stud Alcohol. 2001;62(2):257-61.

22. Lahaut VMHCJ, Jansen HAM, van de Mheen D, Garretsen HFL. Non-response bias in a sample survey on alcohol consumption. Alcohol Alcohol. 2002;37(3):256-60.

23. Hoeymans N, Feskens EJM, Van Den Bos GAM, Kromhout D. Non-response bias in a study of cardiovascular diseases, functional status and self-rated health among elderly men. Age Ageing. 1998;27(1):35-40.

24. Christensen Al, Ekholm O, Gray L, Glumer C, Juel K. What is wrong with non-respondents? Alcohol-, drug- and smoking-related mortality and morbidity in a 12-year follow-up study of respondents and non-respondents in the Danish Health and Morbidity Survey. Addiction. 2015;110(9):1505-12.

25. Jousilahti P, Salomaa V, Kuulasmaa K, Niemelä M, Vartiainen E. Total and cause specific mortality among participants and non-participants of population based health surveys: a comprehensive follow up of 54372 Finnish men and women. J Epidemiol Community Health. 2005;59(4):310-5.

26. Suominen S, Koskenvuo K, Sillanmäki L, Vahtera J, Korkeila K, Kivimäki M, et al. Non-response in a nationwide follow-up postal survey in Finland: a register-based mortality analysis of respondents and non-respondents of the Health and Social Support (HeSSup) Study. BMJ Open. 2012;2(2):e000657.

27. Cohen G, Duffy J. Are nonrespondents to health surveys less healthy than respondents? Journal of Official Statistics. 2002;18(1):13-23.

28. Keyes KM, Rutherford C, Popham F, Martins SS, Gray L. How Healthy Are Survey Respondents Compared with the General Population?: Using Survey-linked Death Records to Compare Mortality Outcomes. Epidemiology. 2018;29(2):299-307.

29. Barchielli A. Nine-year follow-up of a survey on smoking habits in Florence (Italy): higher mortality among non-responders. Int J Epidemiol. 2002;31(5):1038-42.

30. Jones J. The Effects of Non-Response on Statistical Inference. Journal of Health Social Policy. 1996;8(1):49-62.

31. Galea S, Tracy M. Participation Rates in Epidemiologic Studies. Ann Epidemiol. 2007;17(9):643-53.

32. Pace CR. Factors influencing questionnaire returns from former university students. J Appl Psychol. $1939 ; 23(3): 388-97$.

33. Lin I-F, Schaffer NC. Using Survey Participants to Estimate the Impact of Nonparticipation. Public Opin Q. 1995;59:239-58.

34. Donald MN. Implications of Nonresponse for the Interpretation of Mail Questionnaire Data. Public Opinion Quarterly. 1960;24(1):99.

35. Ferber R. The Problem of Bias in Mail Returns: A Solution. Public Opinion Quarterly. 1948;12(4):669.

36. Wellman JD, Hawk EG, Roggenbuck JW, Buhyoff GJ. Mailed Questionnaire Surveys and the Reluctant Respondent: An Empirical Examination of Differences Between Early and Late 
Respondents. Journal of Leisure Research. 1980;12(2):164-73.

37. Siemiatycki J, Campbell S. Nonresponse bias and early versus all responders in mail and telephone surveys. Am J Epidemiol. 1984;120(2):291-301.

38. Haring R, Alte D, Völzke H, Sauer S, Wallaschofski H, John U, et al. Extended recruitment efforts minimize attrition but not necessarily bias. J Clin Epidemiol. 2009;62(3):252-60.

39. Kypri K, Samaranayaka A, Connor J, Langley JD, Maclennan B. Non-response bias in a web-based health behaviour survey of New Zealand tertiary students. Prev Med. 2011;53(4-5):274-7.

40. Kypri K, Stephenson S, Langley J. Assessment of Nonresponse Bias in an Internet Survey of Alcohol Use. Alcoholism: Clinical \& Experimental Research. 2004;28(4):630-4.

41. Meiklejohn J, Connor J, Kypri K. The Effect of Low Survey Response Rates on Estimates of Alcohol Consumption in a General Population Survey. PLoS ONE. 2012;7(4):e35527.

42. Boniface S, Scholes S, Shelton N, Connor J. Assessment of Non-Response Bias in Estimates of Alcohol Consumption: Applying the Continuum of Resistance Model in a General Population Survey in England. PLOS ONE. 2017;12(1):e0170892.

43. University of Oslo. Service for Sensitive Data. https://www.uio.no/english/services/it/research/sensitive-data/about/index.html. Accessed 15 June 2020.

44. Strand BH, Dalgard OS, Tambs K, Rognerud M. Measuring the mental health status of the Norwegian population: a comparison of the instruments SCL-25, SCL-10, SCL-5 and MHI-5 (SF-36). Nord J Psychiatry. 2003;57(2):113-8.

45. Saunders JB, Aasland OG, Babor TF, De La Fuente JR, Grant M. Development of the Alcohol Use Disorders Identification Test (AUDIT): WHO Collaborative Project on Early Detection of Persons with Harmful Alcohol Consumption-II. Addiction (Abingdon. England). 1993;88(6):791-804.

46. Bøen H, Dalgard OS, Bjertness E. The importance of social support in the associations between psychological distress and somatic health problems and socio-economic factors among older adults living at home: a cross sectional study. BMC Geriatrics. 2012;12(1):27.

47. R Core Team. R: A language and environment for statistical computing. Vienna: R Foundation for Statistical Computing; 2017.

48. Venables WN, Ripley BD. Modern Applied Statistics with S. Fourth ed. New York: Springer; 2002.

49. Leeper TJ. margins: Marginal Effects for Model Objects. R package version 0.3.23.2018.

50. Fox J. Effect Displays in R for Generalised Linear Models. J Stat Softw. 2003;8(15):1-27.

51. Fox J, Weisberg S. An R. Companion to Applied Regression. Thousand Oaks2019. Available from: http://tinyurl.com/carbook.

52. Wickham H. ggplot2: Elegant Graphics for Data Analysis. New York: Springer-Verlag; 2016.

53. Statistics Norway. Educational attainment of the population [Internet]. https://www.ssb.no/en/utdanning/statistikker/utniv (2019). Accessed 28 Feb 2020. 
54. Verlato G, Melotti R, Olivieri M, Corsico A, Bugiani M, Accordini S, et al. Asthmatics and ex-smokers respond early, heavy smokers respond late to mailed surveys in Italy. Respir Med. 2010;104(2):1729.

55. Norwegian Digitalisation Agency. The common contact register, usage statistics.

https://www.difi.no/rapporter-og-statistikk/nokkeltall-og-statistikk/digitalisering/kontakt-ogreservasjonsregisteret. Accessed 18 June 2020.

\section{Figures}

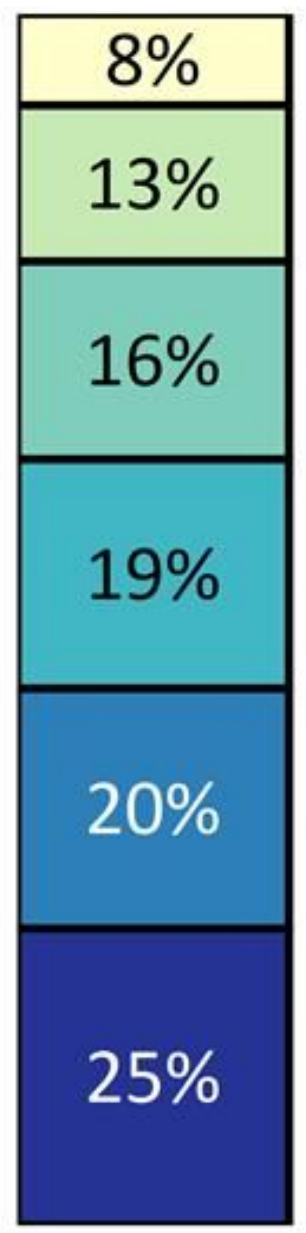

Population

sample $(n=38458)$

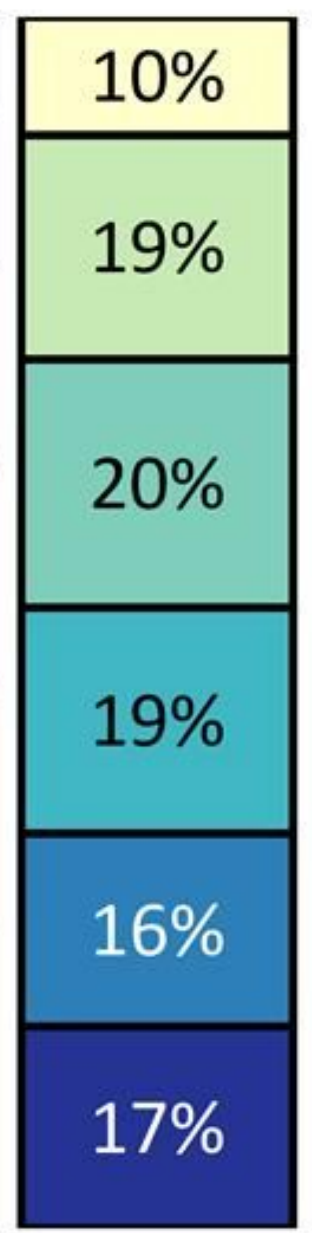

Wave 1 $(n=6950)$

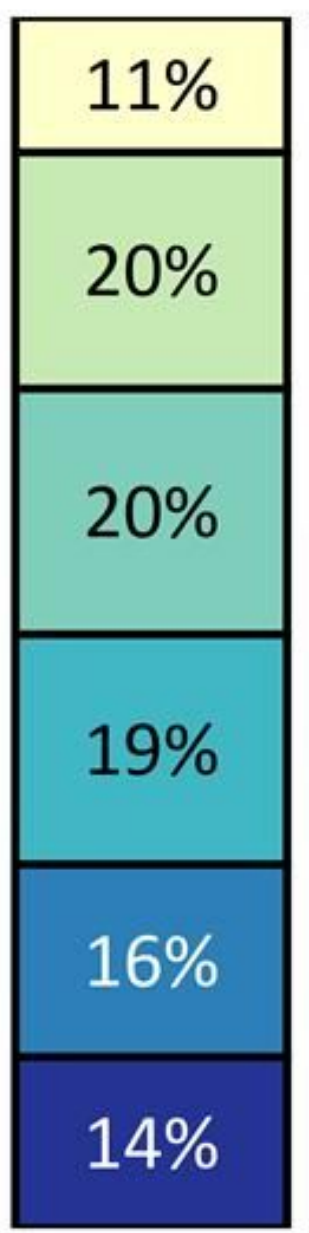

Wave 2 $(n=4950)$

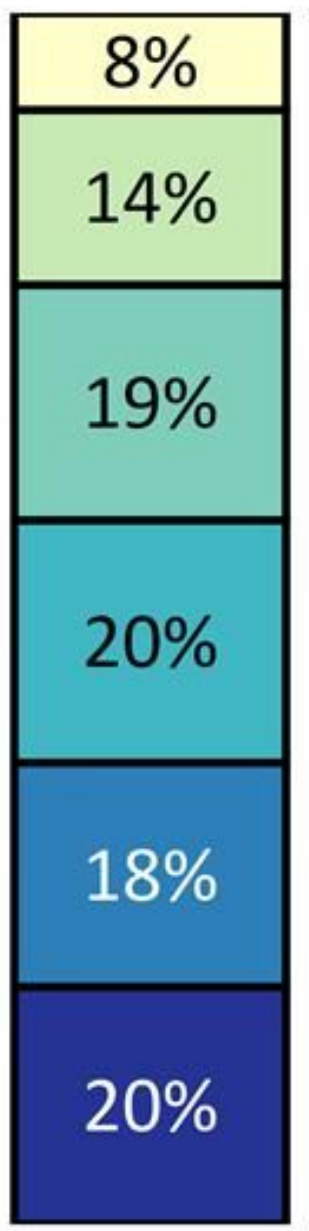

Wave 3 $(n=4045)$
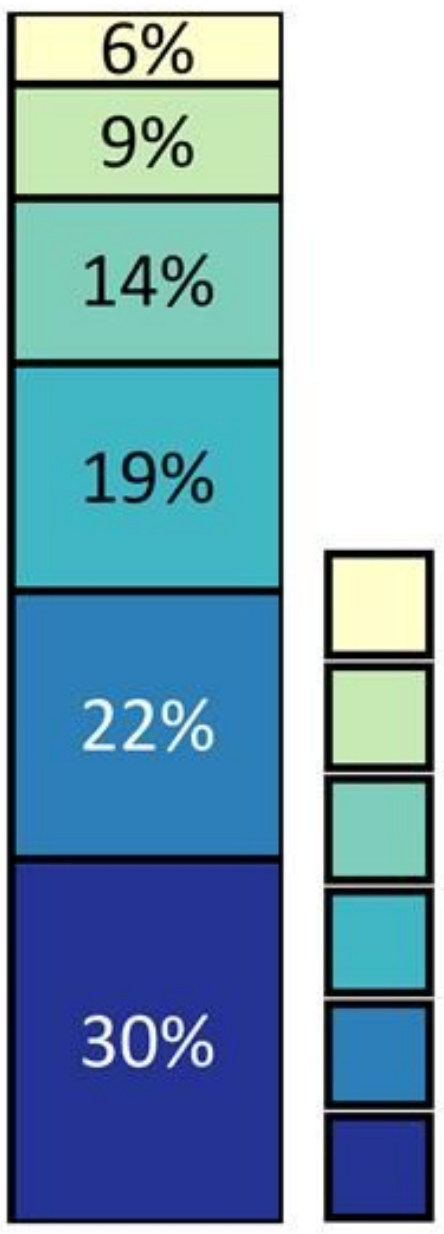

$70+$ 60-69 50-59 40-49 30-39 18-29

\section{Figure 1}

Questionnaire response rate by age group and gender. The overall response rate is shown to the right of each bar, and the response rate for each wave is shown within each segment of the bars. 


\section{Females}

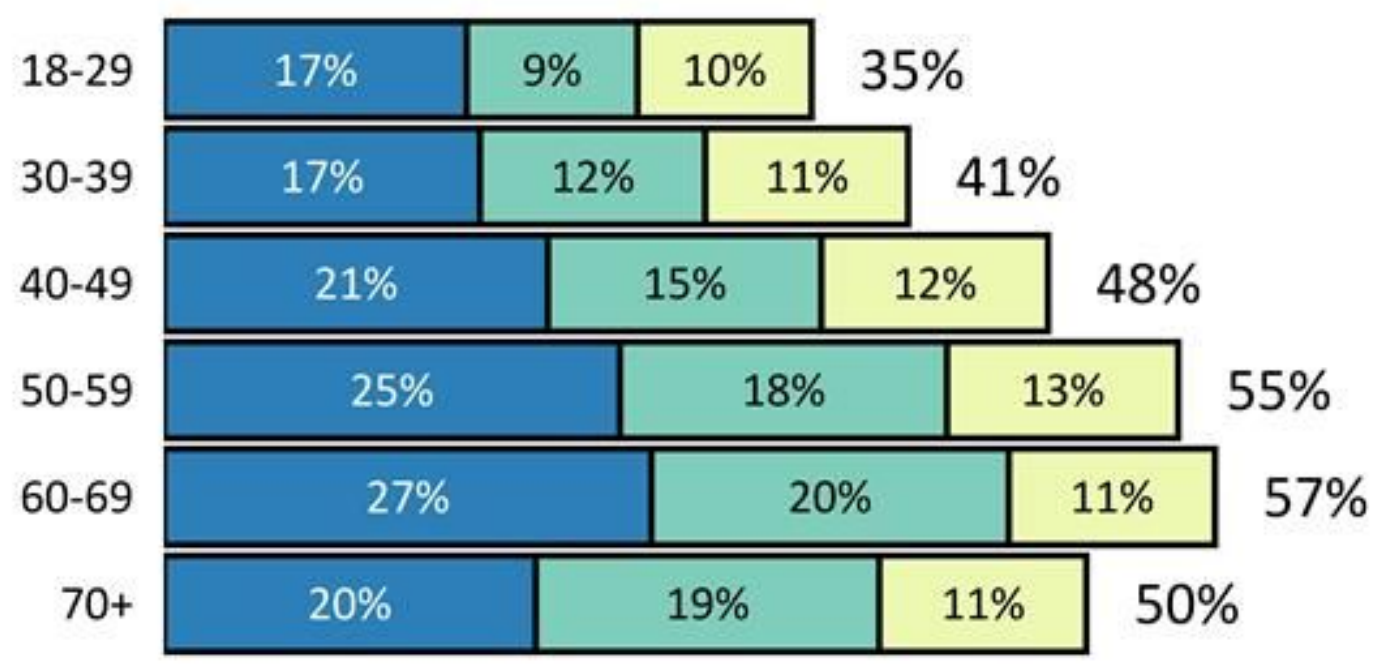

\section{Males}

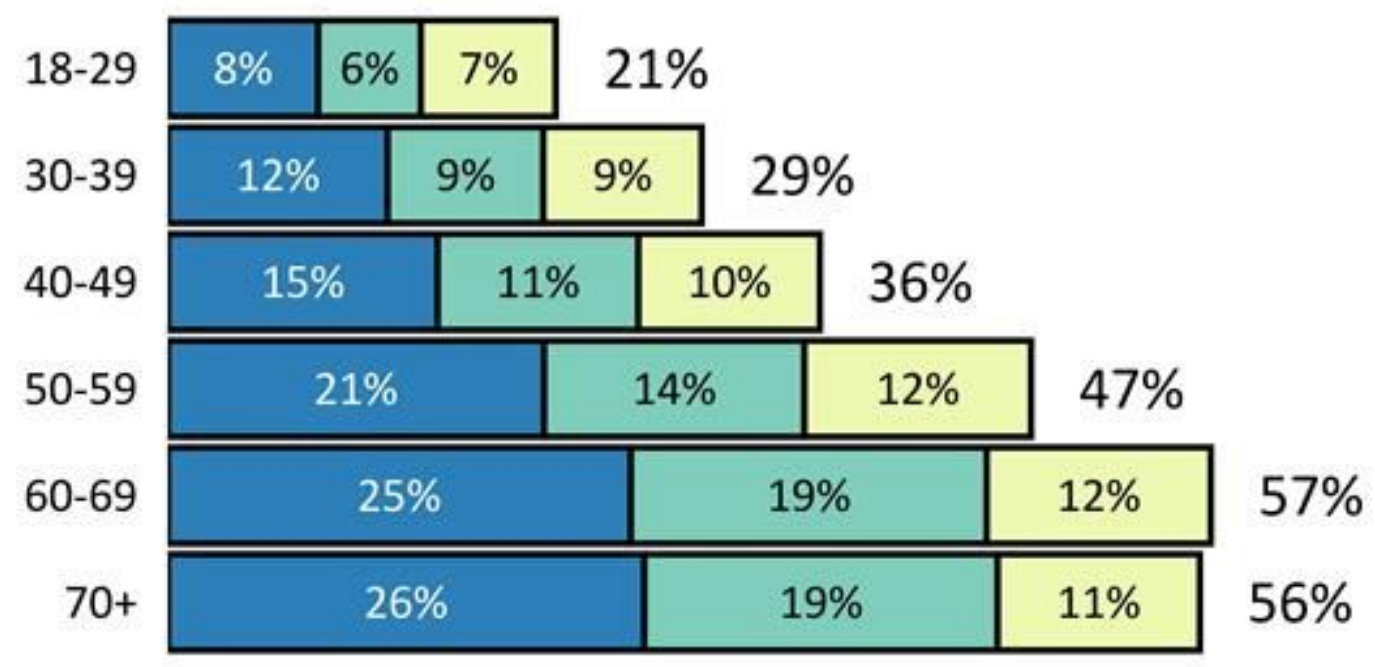

$\square$ Wave $1 \square$ Wave $2 \square$ Wave 3

Figure 2

Age group proportions within the invited sample, each response wave, and non-respondents. 


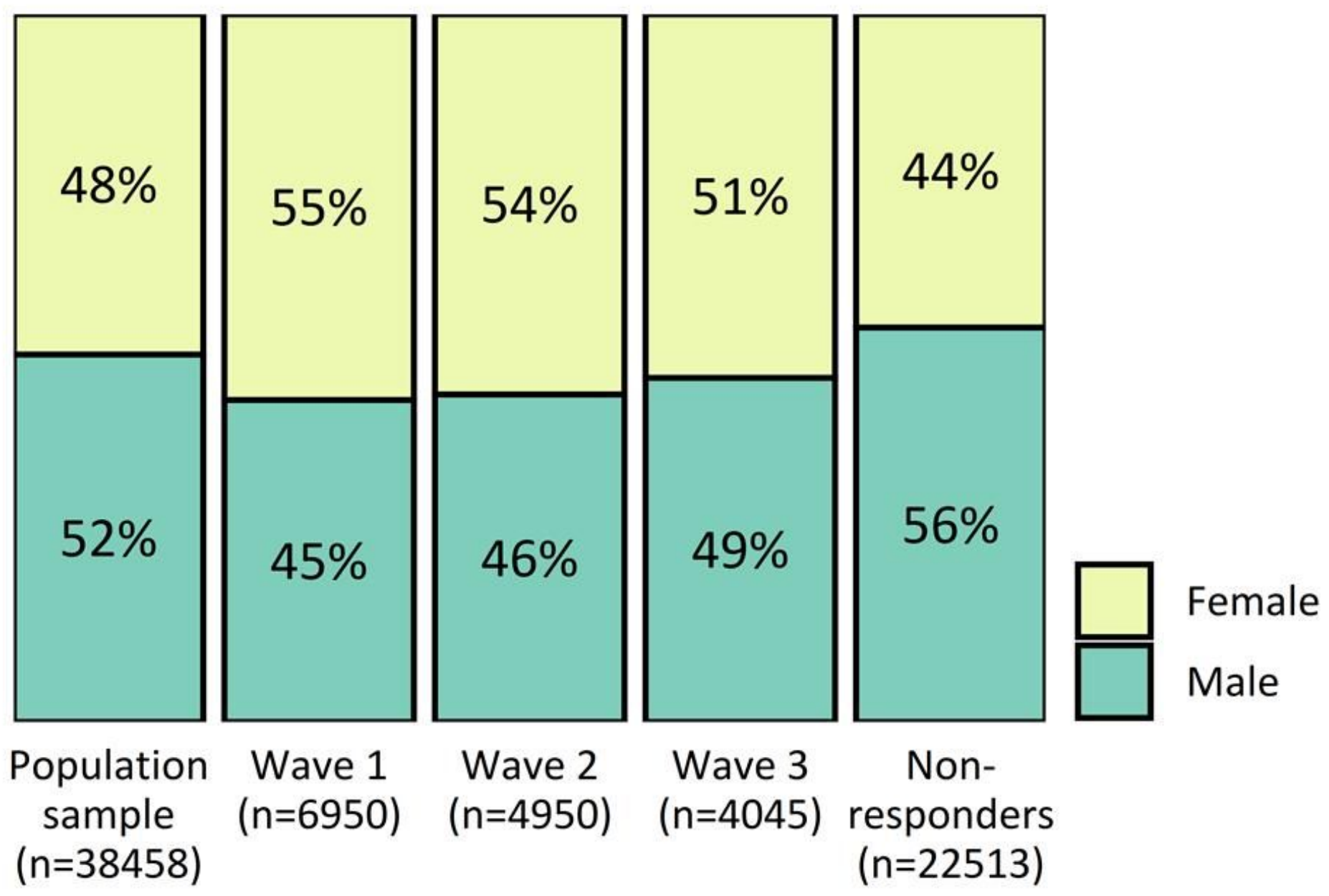

Figure 3

Proportion of males and females within the invited sample, each response wave, and non-respondents 


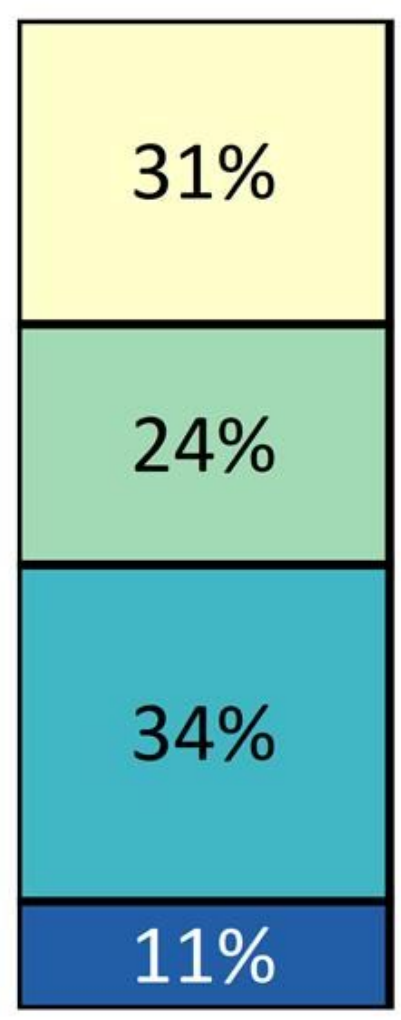

Wave 1

$(n=6950)$

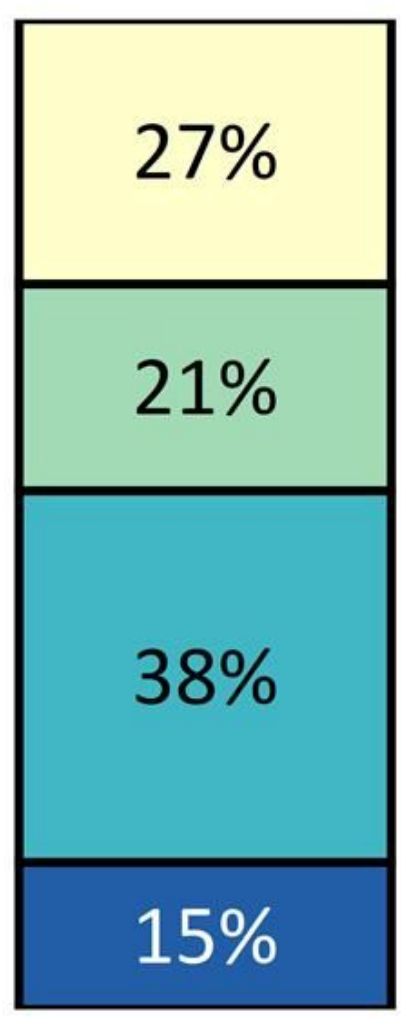

Wave 2

$(n=4950)$

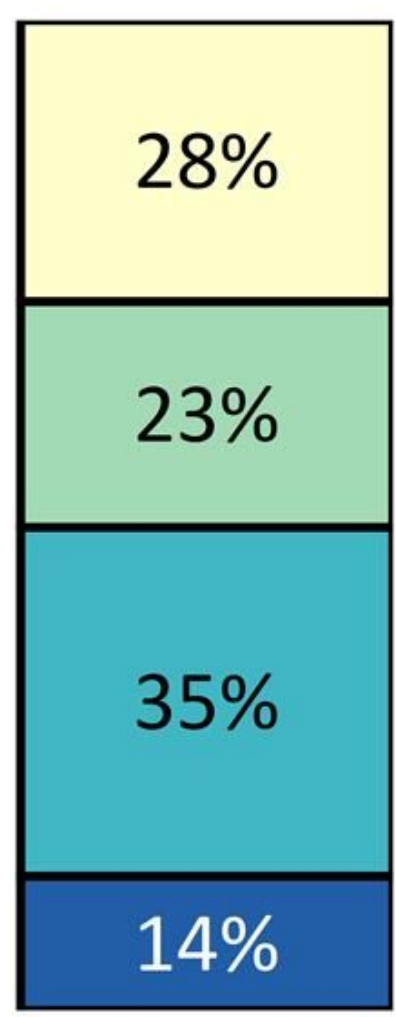

Wave 3

$(n=4045)$

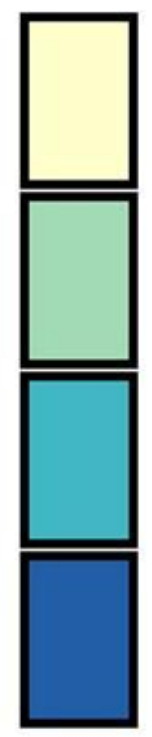

University/college 4 or more years

University/college less than 4 years

Senior high school

Junior high school

Figure 4

Distribution of educational level in each response wave 

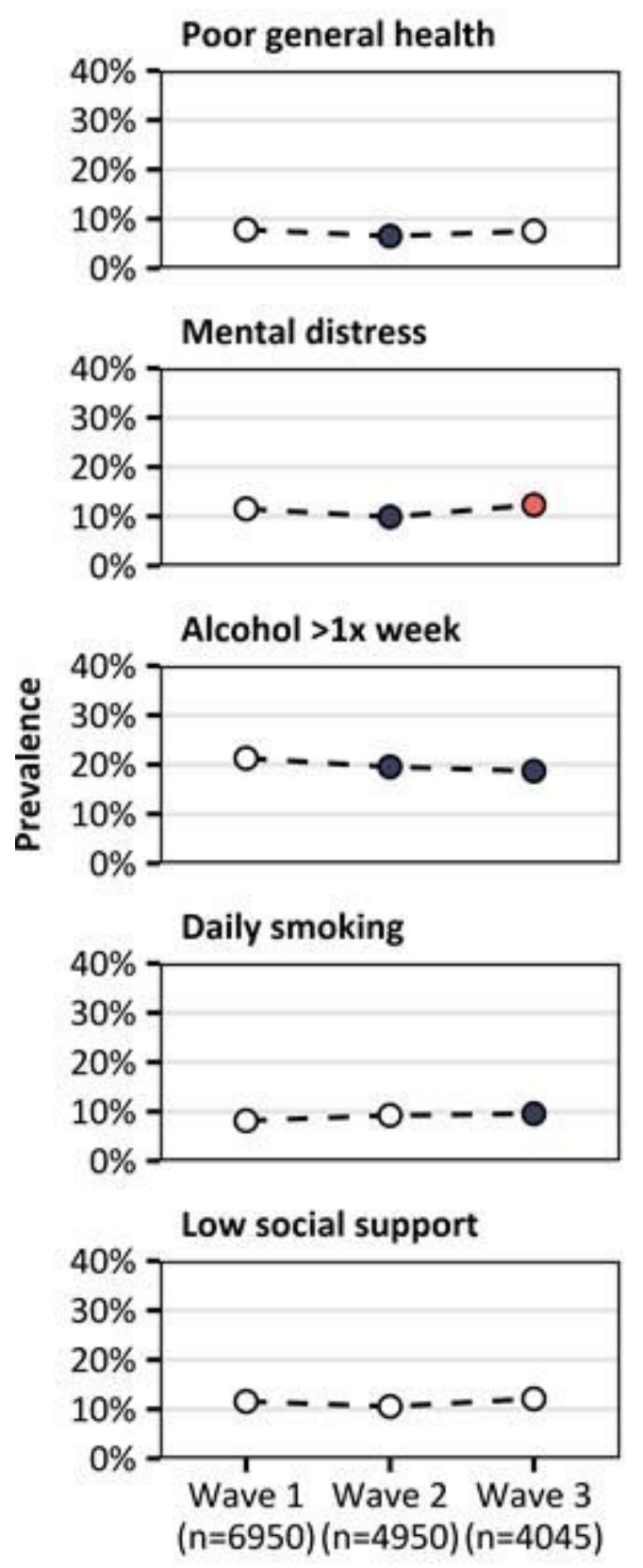

Dissatisfied with life

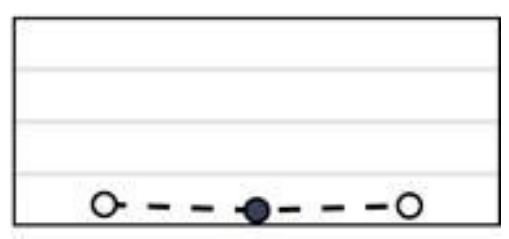

\section{Chronic health problems}

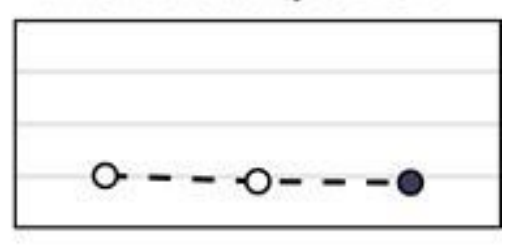

Monthly binge drinking

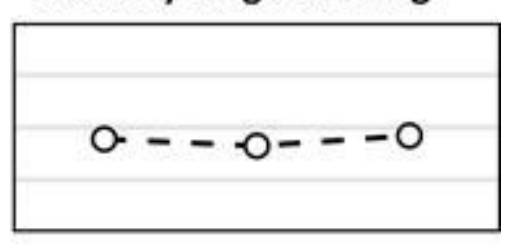

Physically active

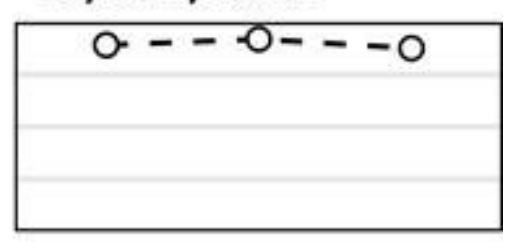

Disability pension

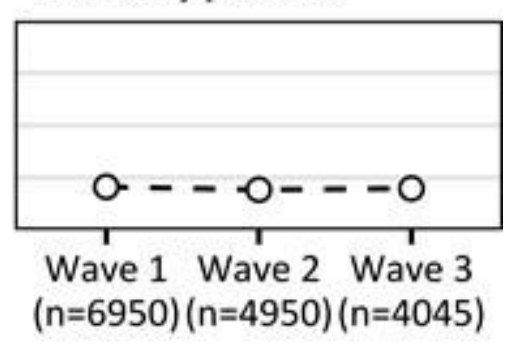

\section{Figure 5}

Prevalence of various health and health-related outcomes among questionnaire respondents in waves 1 , 2 and 3. Red dots indicate significant differences from wave $1(p<0.05)$ and the black dot indicates a significant difference between wave 2 and wave $3(p<0.05)$. 